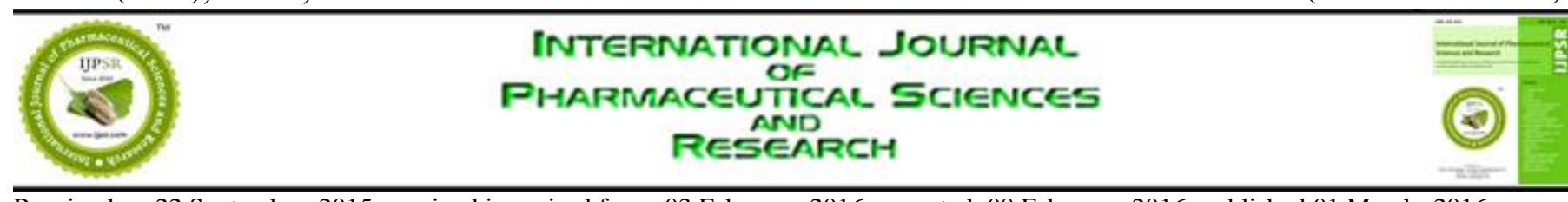

Received on 22 September, 2015; received in revised form, 03 February, 2016; accepted, 08 February, 2016; published 01 March, 2016

\title{
FORMULATION DEVELOPMENT AND EVALUATION OF pH TRIGGERED IN SITU OPHTHALMIC GEL OF EPINASTINE HYDROCHLORIDE
}

\author{
Azmat Shaikh ${ }^{* 1}$, Talat Farheen ${ }^{1}$ and Sadhana Shahi ${ }^{2}$
}

Y. B. Chavan College of Pharmacy ${ }^{1}$, Department of Pharmaceutics, Aurangabad - 431001, Maharashtra, India.

Government College of Pharmacy ${ }^{2}$, Department of Pharmaceutics, Aurangabad - 431005, Maharashtra, India.

Key words:

In situ ophthalmic gel,

$\mathrm{pH}$ triggered polymer, Epinastine hydrochloride, Carbopol, HPMC E-50LV

Correspondence to Author:

Azmat Shaikh

$\mathrm{Ph}$. D Scholar

Y.B. Chavan College of Pharmacy, Department of Pharmaceutics,

Aurangabad, Maharashtra, India431001.

E mail: azmat.pharma@gmail.com

\begin{abstract}
The poor bioavailability of ophthalmic solutions caused by dilution and drainage from the eye can be overcome by using in situ forming ophthalmic drug delivery system prepared from polymer that exhibit reversible liquid-gel phase transition. The objective of the study was to develop optimized formulation of in situ ophthalmic gel of Epinastine hydrochloride, an antihistaminic drug, using a $\mathrm{pH}$ triggered polymer, Carbopol as a gelling polymer and HPMC E-50LV (hydroxyl propyl methyl cellulose) as release retardant. The 32 full factorial design was employed to optimize the formulation considering Carbopol and HPMC as independent variables. The formulations were assessed for appearance, gelling ability, sterility, $\mathrm{pH}$, drug content, viscosity, release through cellophane membrane \& corneal membrane of goat, ocular irritation study \& stability study as per ICH guidelines. Formulations F3 and F7 were found to be the good formulations from the nine formulations developed by 32 factorial design. The study revealed that the in situ system of epinastine hydrochloride sustained the effect of drug to 12 hours. The formulations F3 and F7 extended the release of drug upto 12 hours as compare to marketed product (EPINA eye drops) which released $99.22 \%$ release within $6 \mathrm{hrs}$.
\end{abstract}

INTRODUCTION: Ophthalmic preparations are defined in the USP as "sterile dosage forms, essentially free from foreign particles, suitably compounded and packed for instillation into the eye." In eye drug is administered at various site such as cornea, conjunctiva and sclera for better achievement of bioavailability and required effects related with the therapy.

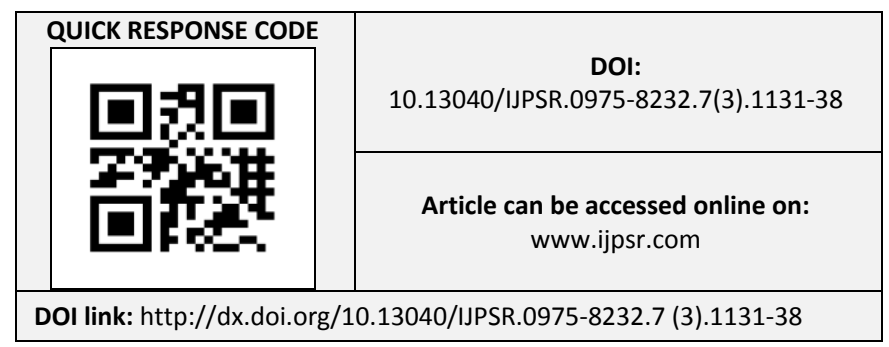

The drugs for allergies, glaucoma, bacterial infections, conjunctivitis, keratitis, local anaesthetics and viral infection can be administered at suitable sites in the eye.

Before reaching the anatomical barrier of the cornea, any drug molecule administered by the topical route has to cross the precorneal barriers. The medication, upon instillation, stimulates the protective physiological mechanisms, i.e., blinking and tears production, which exert defense against ophthalmic drug delivery. Thus the bioavailability of ocular delivery systems is affected by any of the following factors:

a. Low residence volume $(7-10 \mu \mathrm{l})$ 
b. Losses of administered amount due to

- Rapid clearance by lachrymation.

- Non- productive absorption through conjunctiva.

- Drainage through naso-lachrymal drainage.

Following characteristics are required to optimize ocular drug delivery system:

- Good corneal penetration.

- Prolong contact time with corneal tissue.

- Simplicity of instillation for the patient.

- Non-irritant and comfortable form (viscous solution should not provoke lachrymal secretion and reflex blinking).

- Appropriate rheological properties.

Consequently, it is imperative to optimize ophthalmic drug delivery. One of the ways to do so is by addition of polymers of various grades, development of viscous gel, development of colloidal suspension or using erodible or non erodible insert to prolong the pre-corneal drug retention. A significant increase in pre-corneal residence time of drugs and consequently increase in bioavailability can be achieved by using delivery systems based on concept of in situ gel formation. These systems consist of polymers, which undergo reversible sol to gel phase transition in response to physiological stimuli. The sol-gel transition can be induced by a shift in $\mathrm{pH}$, temperature or ion activated systems. This type of gel combines the advantage of a solution (accurate and reproducible administration of drug) and gels (prolonged residence time) for enhancing ocular bioavailability $1-3$.

Epinastine hydrochloride is an antihistaminic drug with potent anti-allergic and modest antiinflammatory activity. It is indicated for the prevention of itching associated with allergic conjunctivitis. The topical Epinastine hydrochloride may be useful for inflammatory conditions in the eye and is approved for the treatment of seasonal allergic conjunctivitis and ocular inflammation. In the present study, an attempt is made to develop $\mathrm{pH}$ triggered in situ gelling ophthalmic delivery system of Epinastine hydrochloride using $\mathrm{pH}$ sensitive polymer, carbopol 974 and viscosity modifier such as HPMC E50LV for sustained drug delivery by enhancing residence time of drug in eye.

\section{MATERIALS AND METHODS: Material:}

The Epinastine hydrochloride and Carbopol 974 was gifted by Cipla Research Center, Mumbai, India. HPMC E-50LV was gifted by Colorcon Asia Pvt. Ltd., Goa. All chemicals used were of analytical grade.

\section{Method:}

Epinastine hydrochloride was characterized by determining its solubility, melting point, UV curve, IR spectrum and DSC graph.

\section{UV method development:}

The method development was done by determining $\lambda_{\max }$, precision, recovery, LOD, LOQ, linearity and by preparing calibration curve ${ }^{4}$.

\section{Preliminary study:}

The preliminary batches of $0.05 \%$ Epinastine hydrochloride were formulated using Carbopol 974, HPMC E-50LV, Benzalkonium chloride, buffering agent and disodium edetate ${ }^{5}$. The batches were evaluated for in vitro in situ gelation in Artificial Tear Fluid (ATF) and for viscosity to optimize the concentration of Carbopol 974 and HPMC E-50LV for final formulation as shown in Table 1.

(-): The solutions which did not undergo phase transition at all.

(+): The solutions which exhibited phase transition only after $60 \mathrm{sec}$. and the formed gels which collapsed within 1-2 hrs.

$(++)$ : The solutions which formed the gels after 60 sec. however, the gels formed did not remain stable for more than $3 \mathrm{hrs}$. 
(+++): The solutions which exhibited phase transition within $60 \mathrm{sec}$. and the gels so formed remained stable for more than 7-8 hrs.

The above preliminary batches indicated that;

- HPMC alone does not possess any in situ gelling properties (P1 to $\mathrm{P} 5)$.

- Carbopol above the conc. of $0.075 \%$ forms in situ gel in artificial tear fluid (ATF) (P7 to P10).
- Carbopol above $0.4 \%$ conc. produces formulation of high viscosity that is not suitable for instillation into the eyes (P11 to P12).

- Carbopol above the conc. of $0.6 \%$ produced direct gel formulation (P13 to P14).

Hence the level of Carbopol was decided based on in situ gelling capacity between 0.1 to $0.3 \%$.

TABLE 1: FORMULATION OF PRELIMINARY BATCHES AND ITS EVALUATION

\begin{tabular}{ccccc}
\hline $\begin{array}{c}\text { Batch } \\
\text { Code }\end{array}$ & $\begin{array}{c}\text { Carbopol 974 } \\
\text { (\% concentration) }\end{array}$ & $\begin{array}{c}\text { HPMC E-50LV } \\
\text { (\%concentration) }\end{array}$ & $\begin{array}{c}\text { Gelling } \\
\text { Capacity }\end{array}$ & Viscosity (cps) \\
\hline P1 & - & 0.6 & No Gelation & 17 \\
P2 & - & 0.8 & No Gelation & 30 \\
P3 & - & 1.0 & No Gelation & 38 \\
P4 & - & 2.0 & No Gelation & 50 \\
P5 & - & 3.0 & No Gelation & 68 \\
P6 & 0.05 & 0.5 & - & 30 \\
P7 & 0.075 & 0.6 & + & 38 \\
P8 & 0.1 & 0.7 & ++ & 50 \\
P9 & 0.2 & 0.8 & +++ & 120 \\
P10 & 0.3 & 0.9 & +++ & 170 \\
P11 & 0.4 & 1.0 & Viscous Liquid & 242 \\
P12 & 0.5 & 1.5 & Viscous Liquid & 416 \\
P13 & 0.6 & 2.0 & Direct Gelling & 590 \\
P14 & 0.7 & 2.5 & Direct Gelling & 703 \\
\hline
\end{tabular}

Optimization by $3^{2}$ factorial design:

The $0.05 \% \quad \mathrm{w} / \mathrm{v}$ solutions of Epinastine hydrochloride were prepared using different concentrations of Carbopol as per Table 2. The two independent variables selected were HPMC E-
50LV $\left(\mathrm{X}_{1}\right)$ and Carbopol $974\left(\mathrm{X}_{2}\right)$, and the dependent variables were viscosity $\left(\mathrm{Y}_{1}\right)$ and release of drug $\left(\mathrm{Y}_{2}\right)$. The factorial designed batches are shown in Table 2.

TABLE 2: FORMULATION OF FACTORIAL BATCHES OF EPINASTINE HYDROCHLORIDE

\begin{tabular}{|c|c|c|c|c|c|c|c|c|c|}
\hline \multirow[t]{2}{*}{ Ingredients (g) } & \multicolumn{9}{|c|}{ Formulation Code } \\
\hline & F1 & F2 & F3 & F4 & F5 & F6 & F7 & F8 & F9 \\
\hline Epinastine hydrochloride & 0.05 & 0.05 & 0.05 & 0.05 & 0.05 & 0.05 & 0.05 & 0.05 & 0.05 \\
\hline HPMC E-50LV $\left(\mathrm{X}_{1}\right)$ & 0.6 & 0.8 & 1.0 & 0.6 & 0.8 & 1.0 & 0.6 & 0.8 & 1.0 \\
\hline Carbopol $974\left(\mathrm{X}_{2}\right)$ & 0.1 & 0.1 & 0.1 & 0.2 & 0.2 & 0.2 & 0.3 & 0.3 & 0.3 \\
\hline Monobasic sodium phosphate & 0.5 & 0.5 & 0.5 & 0.5 & 0.5 & 0.5 & 0.5 & 0.5 & 0.5 \\
\hline Disodium edetate & 0.01 & 0.01 & 0.01 & 0.01 & 0.01 & 0.01 & 0.01 & 0.01 & 0.01 \\
\hline Benzalkonium chloride (BKC)* & 0.01 & 0.01 & 0.01 & 0.01 & 0.01 & 0.01 & 0.01 & 0.01 & 0.01 \\
\hline $\begin{array}{c}\text { Sodium hydroxide/Hydrochloric acid } \\
\text { Purified water }\end{array}$ & \multicolumn{9}{|c|}{$\begin{array}{c}\text { q.s. to adjust } \mathrm{pH} \\
\text { q.s.to } 100 \mathrm{ml} \\
\end{array}$} \\
\hline
\end{tabular}

*The Benzalkonium chloride solution to be added as $50 \% \mathrm{w} / \mathrm{v}$ solution

Preparation of in situ Gelling Ophthalmic Formulation:

Accurately weighed quantity of monobasic sodium phosphate and disodium edetate were dissolved in a part quantity of purified water. Separately the carbopol was sprinkled over a part quantity of hot water (temperature $60-70^{\circ} \mathrm{C}$ ) and was allowed to hydrate completely to produce transparent viscous solution. Both the solutions are mixed which results into drop in viscosity of carbopol solution. The $\mathrm{pH}$ 
of this solution was adjusted to $7.0 \pm 0.1$ with $0.1 \mathrm{~N}$ sodium hydroxide or hydrochloric acid. The viscosity of formulation was found to be increased during $\mathrm{pH}$ adjustment step. The above solution was subjected to bulk autoclaving (Solution A). Separately in a part quantity of water epinastine hydrochloride was dissolved. In this solution benzalkonium chloride solution was added under slow stirring and this solution was filtered through $0.22 \mu \mathrm{m}$ polyether sulphone (PES) membrane filter (Make: Pall) (Solution B).

The solution B was mixed slowly to solution A with continuous mechanical stirring at $100 \mathrm{rpm}$ to produce clear solution. The formulation was filled into LDPE bottle with translucent droptainer and white opaque cap (Make: Rexam).

\section{Evaluation of in situ gelling formulations:}

The ophthalmic formulations were evaluated for various physical and performance characteristics i.e. for appearance/ clarity, $\mathrm{pH}$, gelling ability, sterility, stability and viscosity. The test for sterility was confirmed by method B described in USP and the end point was judged visually noting the presence of turbidity in the inoculated media. Both positive and negative controls were also maintained

simultaneously. The method of detection was visual inspection of turbidity.

The test for gelling ability was conducted using Artificial tear fluid (ATF). The transition of solution to viscous gel was observed visually and numerical scores were assigned depending upon the quickness of gel formation and time taken for collapse of gel structure on shaking the vials. The drug content was determined spectrophotometrically.

\section{In vitro drug release study:}

In vitro release was performed through cellophane membrane (pore size $0.45 \mu \mathrm{m}$ ) using modified dissolution testing apparatus. The USP type-I apparatus (Basket type) was modified by replacing the basket with glass cylinder of same size. The glass cylinder was attached to the shaft of USP apparatus-1 (Basket type) instead of basket (as shown in Fig.1). The dissolution media was ATF (50 ml) maintained at $37 \pm 0.5{ }^{\circ} \mathrm{C}$. The sample (1 $\mathrm{ml})$ was withdrawn at regular interval of $1 \mathrm{hr}$ till 12 $\mathrm{hr}$ and it was replaced immediately with the same volume of ATF. The samples withdrawn were analyzed for drug content ${ }^{7}$.

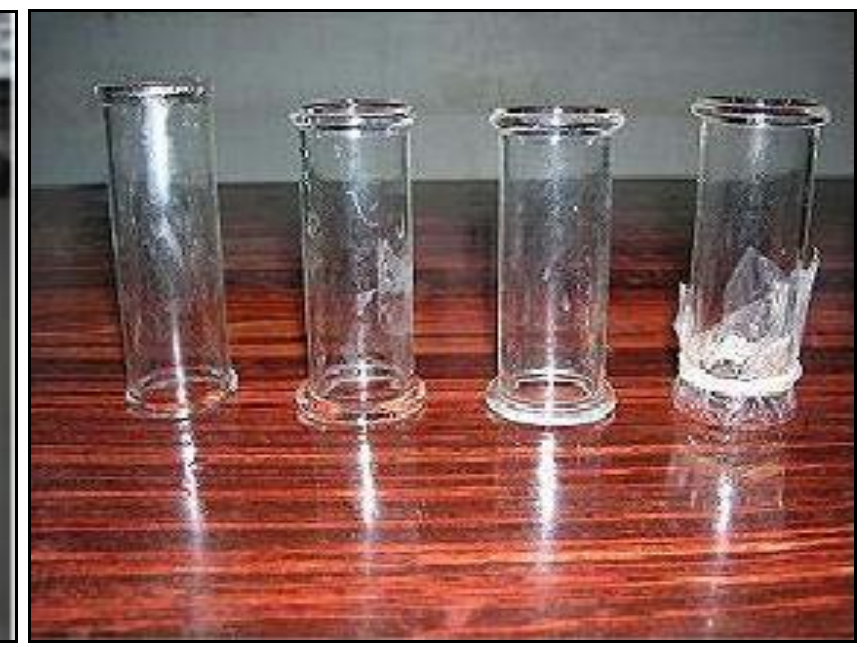

FIG. 1: MODIFIED DISSOLUTION TEST APPARATUS

\section{Ocular irritation study in rabbits:}

The selected formulations F3 \& F7 were instilled $(0.1 \mathrm{ml})$ into the eye of rabbit. The eyeball was observed for acute toxicity symptoms i.e. redness, inflammation \& tear flux at an interval of $1,24,48$, $72 \mathrm{hrs}$ and after 1 week. The ocular irritation study was measured on a scale of 0 to $4^{8}$.

\section{Stability study:}

The formulations F3 and F7 were subjected to stability studies as per ICH guidelines. The formulations were assessed for appearance, gelation ability, sterility, $\mathrm{pH}$, drug content and viscosity ${ }^{12}$. 


\section{Population bioequivalence study:}

Population bioequivalence study was done by measurement of drop weights of formulation. The weight of each drop was measured for 10 drops each at $45^{\circ} \& 90^{\circ}$ angle as per ASTM guideline ${ }^{15}$. The study was conducted on 10 different bottles and mean drop weight of 10 bottles was compared with marketed formulation to establish the population bioequivalence.

\section{RESULT AND DISCUSSION:}

The drug, Epinastine hydrochloride was characterized by observing its UV, DSC and IR spectrum. The formulated ophthalmic formulations were evaluated for various physical and performance characteristics.

The formulation of preliminary batches revealed in vitro gelation above the concentration of $0.075 \%$ Carbopol 974 and no gelation was observed below $0.075 \%$ of Carbopol 974. The ophthalmic formulations were observed carefully for color, odor and presence of suspended particulate matter if any. The clarity of solutions was further assessed by observing them against a dark and white background as described in the USP. The $\mathrm{pH}$ of all the formulations was found to be in the range of 7.0-7.5.

The ideal value of viscosity for ophthalmic solutions is important as it affects proper instillation of drops from containers, good spreadability of solutions in the eye and improved contact time in the eye. All the solutions were readily satisfying the parameter and hence were considered acceptable.
Viscosity increased with the increase in the concentration of carbopol from 0.1 to $0.3 \%$. Similarly viscosity increased with the increase in the concentration of HPMC E-50LV for concentration from 0.6 to $1.0 \%$. Increase in viscosity of ophthalmic solutions after instillation in eye was a desired feature for the purpose of sustaining therapeutics actions of the antihistaminic agent, epinastine hydrochloride, by providing increased precorneal residence time. The increase in viscosity was achieved due to the inclusion of carbopol which undergoes gelation at physiological $\mathrm{pH}$. The results are recorded in Table 3. The test for sterility for the selected formulations indicated no tubidity after incubation at specified conditions upto 14 days, while the positive controls revealed dense turbidity.

\section{TABLE 3: VISCOSITY VALUES FOR OPHTHALMIC} FORMULATION

\begin{tabular}{ccc}
\hline Sr. no. & Batch code & Viscosity (cps) $^{*}$ \\
\hline 1 & F1 & 80.23 \\
2 & F2 & 85.98 \\
3 & F3 & 90.45 \\
4 & F4 & 115.65 \\
5 & F5 & 120.48 \\
6 & F6 & 130.45 \\
7 & F7 & 165.94 \\
8 & F8 & 169.74 \\
9 & F9 & 178.62 \\
\hline *Brooke Field LVDVII + Viscometer- spindle no. S18 at 30 \\
rpm
\end{tabular}

The test for in vitro gelation ability was performed to assess the gel characteristics which would affect drug release in the ATF. The numerical scores for gelling ability of solutions were found to vary with change in the concentration of Carbopol as shown in Table 4.

TABLE 4: GELLING CAPACITY OF OPHTHALMIC FORMULATIONS

\begin{tabular}{cccc}
\hline $\begin{array}{c}\text { Formulation } \\
\text { Code }\end{array}$ & $\begin{array}{c}\text { Carbopol 974 } \\
(\% \mathbf{w} / \mathbf{v})\end{array}$ & $\begin{array}{c}\text { HPMC E50 LV } \\
(\boldsymbol{\%} \mathbf{~ w / v})\end{array}$ & Gelling ability \\
\hline F1 & 0.1 & 0.6 & + \\
F2 & 0.1 & 0.8 & + \\
F3 & 0.1 & 1 & ++ \\
F4 & 0.2 & 0.6 & + \\
F5 & 0.2 & 0.8 & ++ \\
F6 & 0.2 & 1 & ++ \\
F7 & 0.3 & 0.6 & ++ \\
F8 & 0.3 & 0.8 & ++ \\
F9 & 0.3 & 1 & +++ \\
\hline
\end{tabular}

(-): No gelation

$(+)$ : Gels after few seconds, dissolves rapidly (within 1-2 h)

$(++)$ : Gelation immediately, remains for few $\mathrm{h}(3-4 \mathrm{~h})$

$(+++)$ : Gelation immediately, remains for extended period (more than 6-8 $\mathrm{h}$ ) 
The phase transition of the ophthalmic formulations containing carbopol was found to be concentration dependent. Thus, the increased concentration of carbopol caused decrease in the time taken for gelation. The drug content was determined spectrophotometrically.

In vitro release through cellophane membrane revealed that with the increase in the concentration of HPMC E-50LV the release decreased due to the formation of gel structure. As the conc. Of carbopol increased from $0.1 \%$ to $0.3 \%$ there was further retardation in the release (batches F4, F5, F6 and F7, F8, F9). This may be accounted for the reduction in number and dimensions of the channels in the gel structure due to enhanced viscosity of gel. The kinetics of drug release mechanism (PCP Disso version 2.08 software) revealed matrix model kinetics.

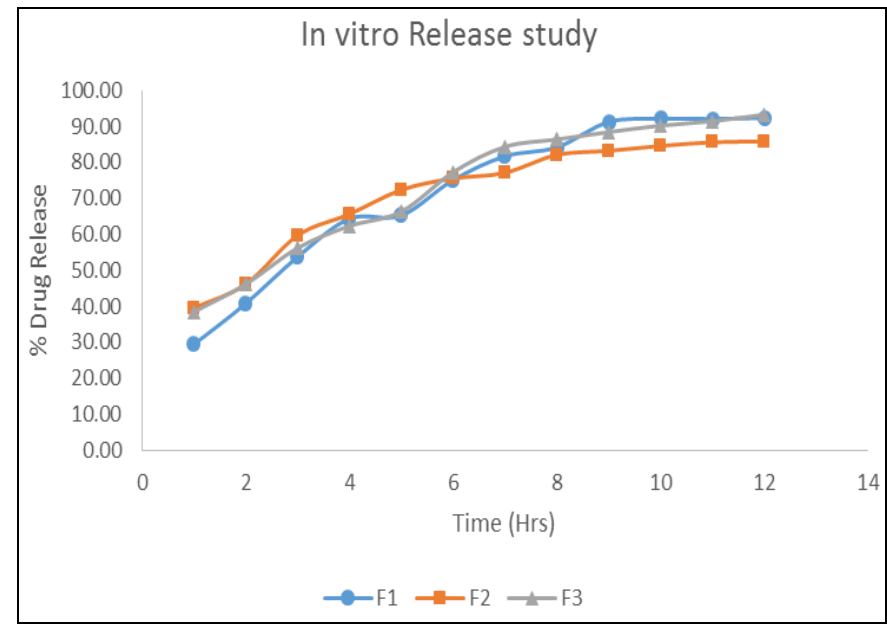

FIG.2: PERCENTAGE DRUG RELEASE FROM FACTORIAL BATCHES (F1, F2 \&F3)

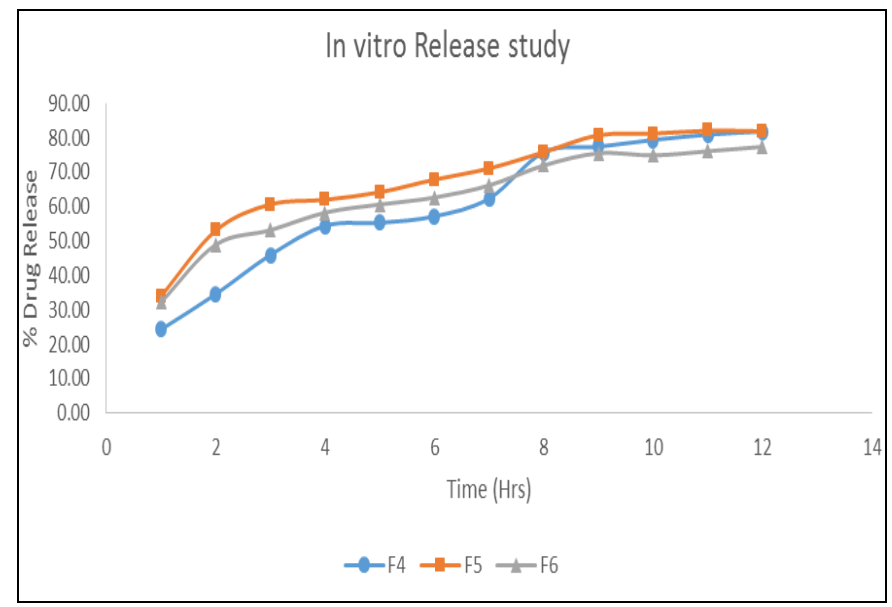

FIG.3: PERCENTAGE DRUG RELEASE FROM FACTORIAL BATCHES (F4, F5 \&F6)

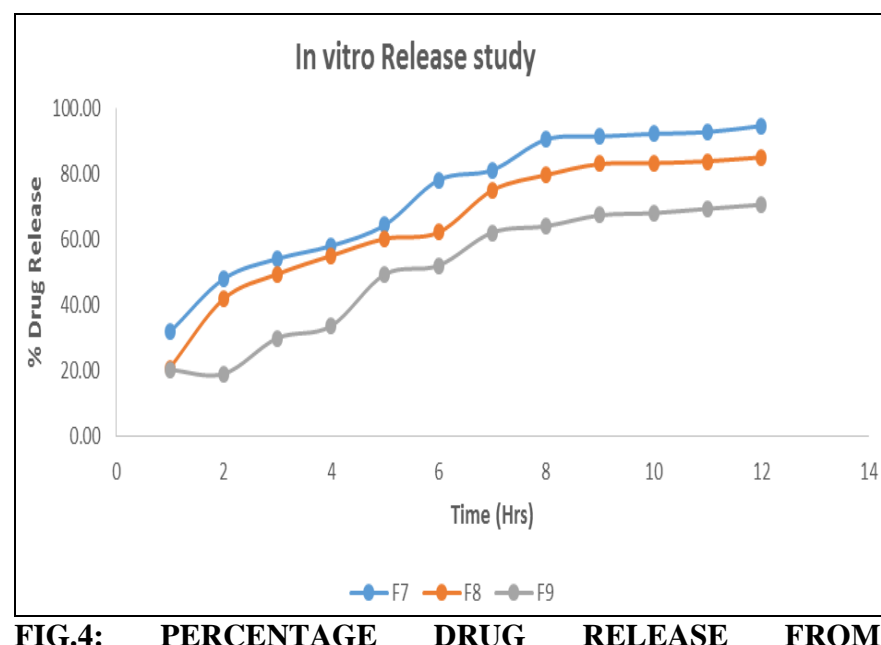

FACTORIAL BATCHES (F7, F8 \& F9)

The release of epinastine hydrochloride through goat cornea was slower as compared to the release through cellophane membrane. Hence, the formulation containing carbopol is found to be effective in sustaining the release of epinastine hydrochloride (over the period $12 \mathrm{hrs}$ ) as shown in Fig.5.

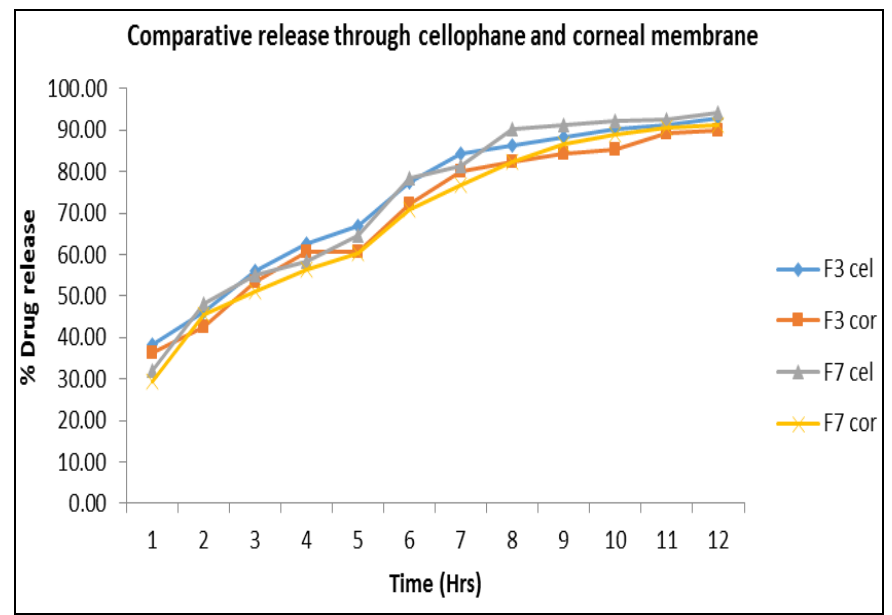

FIG.5: PERCENTAGE DRUG RELEASE THROUGH CELLOPHANE AND CORNEAL MEMBRANE

F3 cel: Drug release through cellophane membrane

F3 cor: Drug release through corneal membrane

F7 cel: Drug release through cellophane membrane

F7 cor: Drug release through corneal membrane

The ocular irritation study revealed the numerical score for the formulation F3 and F7 read zero, an indication of safe and non irritant for administration. The findings of the stability study 
suggested no significant change in the selected physical parameters for the formulations F3 and F7. The release profile of the F3 and F7 were compared with that of marketed preparation (EPINA Eye drops), as shown in figure 6 . The formulation F3 \& F7 indicated sustained release of drug upto $12 \mathrm{hr}$ as compared to marketed product (EPINA eye drops) which released $99.22 \%$ release within $6 \mathrm{hrs}$.

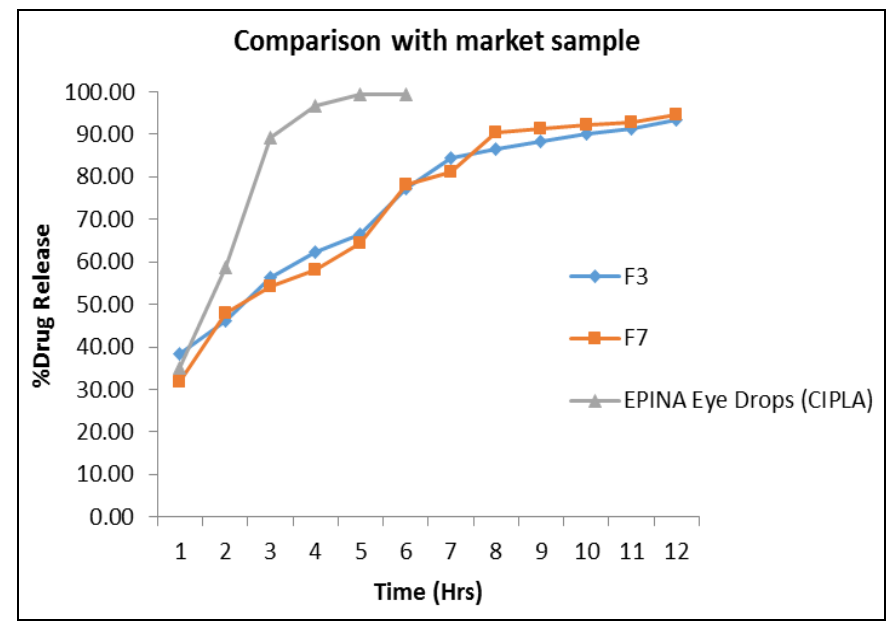

FIG.6: COMPARISON OF RELEASE PROFILE WITH MARKETED PRODUCT

Population bioequivalence was carried out by comparing mean drop weight of developed formulation with marketed product of epinastine hydrochloride [EPINA Eye Drops manufactured by CIPLA]. The results are as appended in Table 5.

TABLE 5: POPULATION BIOEQUIVALENCE STUDY

\begin{tabular}{ccc}
\hline \multicolumn{3}{c}{ Drop weight (in mg)* } \\
\hline No of bottles & $\begin{array}{c}\text { F3 } \\
\text { (Test) }\end{array}$ & $\begin{array}{c}\text { Epina (Cipla) } \\
\text { (Reference) }\end{array}$ \\
\hline Bottle-1 & 27.6 & 28.5 \\
Bottle-2 & 28.8 & 29.6 \\
Bottle-3 & 29.3 & 34.6 \\
Bottle-4 & 31.4 & 35.8 \\
Bottle-5 & 32.2 & 32.4 \\
Bottle-6 & 34.5 & 36.7 \\
Bottle-7 & 32.9 & 31.2 \\
Bottle-8 & 33.7 & 34.2 \\
Bottle-9 & 33.5 & 30.7 \\
Bottle-10 & 34.6 & 33.1 \\
Mean & $\mathbf{3 1 . 8 5}$ & $\mathbf{3 2 . 6 8}$ \\
Min & 27.6 & 28.5 \\
Max & 34.6 & 36.7 \\
Standard deviation & 2.49 & 2.69 \\
\% RSD & 7.83 & 8.24 \\
No of drops (N) & 200 & 200 \\
Population & & \\
Bioequivalence & & \\
*Mean drop weight value of 10 drops each at $45^{\circ}$ and $90^{\circ}$ \\
angle. $\quad$
\end{tabular}

CONCLUSION: An attempt has been made to develop in situ gelling systems of Epinastine hydrochloride, anti-allergic \& anti-inflammatory drug, to increase the ocular residence time. The variables Carbopol and HPMC E-50LV exhibited significant effect on the responses viscosity and release of the formulation. A stable in situ gelling system of Epinastine hydrochloride has been successfully developed using Carbopol and HPMC E-50LV and is a promising approach for the treatment seasonal allergic conjunctivitis to prevent the ocular itching.

ACKNOWLEDGEMENT: Authors wish to acknowledge to Maharashtra Institute of Technology (M.I.T) for their valuable support for testing and analysis

\section{REFERENCES:}

1. Srividya B, Cardoza RM, Amin PD: Sustained ophthalmic delivery of Ofloxacin from a $\mathrm{pH}$ trigerred In situ gelling system. Journal of Control Release 2001; 73: 205-211.

2. Jain SP, Shah SP, Namita R, Pirthi PS, Amin PD: In situ ophthalmic gel of Ciprofloxacin Hydrochloride for once a day sustained delivery, Drug Development and Industrial Pharmacy 2008; 34: 445-452.

3. Charoo NA, Kohli K, Ali A: Preparation of In situ forming ophthalmic gels of Ciprofloxacin Hydrochloride for treatment of bacterial conjunctivitis: In vitro and In vivo studies. Journal of Pharmaceutical Sciences 2003; 92.

4. Liu Z, Li J, Nie S, Hui Lui, Ding P, Pah W: Study of an Alginate/HPMC based In situ gelling ophthalmic delivery system for Gatifloxacin. International Journal of Pharmaceutics 2006; 315: 12-17.

5. Doijad RC, Manvi FV, Malleshwara Rao VSN, Alase P: Sustained ophthalmic delivery of Gatifloxacin from In situ gelling system. Indian Journal of Pharmaceutical Sciences 2006; 814-818.

6. Pandit JK, Bharathi D, Srinatha A, Ridhurkar DN, Singh S: Long acting ophthalmic formulation of Indomethacin: Evaluation of alginate gel system. Indian Journal of Pharmaceutical Sciences 2007; 69: 37-40.

7. Amal El-Kamel, Heba Al-Dosari, Fahad Al-Jenoobi: Environmentally responsive ophthalmic gel formulation of Carteolol Hydrochloride. Drug Delivery 2006; 13: 55-59.

8. Bharath S, Sindhu A, Sharon F, Basavaraj BV, Deveshwaran R, Madhavan V: Sustained ophthalmic delivery of Ofloxacin from an Ion activated In situ gelling system. Journal of Pharmaceutical Sciences 2009; 22: 175179.

9. Cohen S, Lobel E, Trevgoda A, Peled Y: A novel In situ forming ophthlamic drug delivery system from alginates undergoing gelation in eye. Journal of Control Release 1997; 44: 201-208.

10. Shivanand, Hiremath SP, Fatima SD, Abida N, Vilas GJ, Jameel SM, Sreenivas SA, Hasanpasha N, Ahemad A: Formulation and evaluation of a novel In situ gum based ophthalmic drug delivery system of Linezolid. Science Pharm 2008; 76: 515-532. 
11. Agarwal ML, Agarwal S, Gupta LC: Ophthalmology, 1st ed., Jaypeee Brothers, 1996; 42-58.

12. Pandit JK, Bharathi D, Srinatha A, Ridhurkar DN, Singh S: Indian Journal of Pharmaceutical Sciences 2007; 69: 37-40

13. Qi $\mathrm{H}, \mathrm{Wu} \mathrm{C}$ et al: Development of a poloxamer analogs /carbopol based in situ gelling and muco-adhesive ophthalmic delivery system for Puerarin. International Journal of Pharmaceutics 2007; 337: 178-187.

14. Paul RE, Whitchers JP. General Ophthalmology, 16th ed., London: McGraw Hills 2004, 100-135.

15. American Standard for Testing of Material (ASTM) guideline for drop weight study measurement.

How to cite this article:

Shaikh A, Farheen T and Shahi S: Formulation Development and Evaluation of pH Triggered in Situ Ophthalmic Gel of Epinastine Hydrochloride. Int J Pharm Sci Res 2016; 7(3): 1131-38.doi: 10.13040/IJPSR.0975-8232.7(3).1131-38

All ( 2013 are reserved by International Journal of Pharmaceutical Sciences and Research. This Journal licensed under a Creative Commons Attribution-NonCommercial-ShareAlike 3.0 Unported License.

This article can be downloaded to ANDROID OS based mobile. Scan QR Code using Code/Bar Scanner from your mobile. (Scanners are available on Google Playstore) 